\title{
A PROSPECTIVE OBSERVATIONAL STUDY ON HEALTH-RELATED QUALITY OF LIFE IN CHRONIC OBSTRUCTIVE PULMONARY DISEASE PATIENTS BASED ON SEVERITY
}

\author{
JILU DANIEL VARUGHESE*, JAYAKUMARI S
}

Department of Pharmacy Practice, School of Pharmaceutical Sciences, Vels University (vistas), Pallavaram, Chennai, Tamil nadu, India. Email: jilu_jvd@hotmail.com

Received: 15 April 2017, Revised and Accepted: 08 May 2017

\section{ABSTRACT}

Objective: The objective of the study was to determine health-related quality of life (HRQOL) in patients with chronic obstructive pulmonary disease (COPD) and to measure differences in HRQOL according to gender and severity of COPD.

Methods: An observational study was conducted over a period of 9 months. A total of 100 COPD patient's data were collected regarding patients age, gender, smoking status, and clinical characteristics using an SF-12 health survey questionnaire.

Results: The total study population of 100 patients, $78 \%$ were men and $22 \%$ of women with a mean age of $65.4 \pm 13.2$ years. The spirometry measurements, the mean forced expiratory volume 1 (FEV1) value was $57.2 \pm 10.4$. HRQOL correlated significantly with FEV1 values ( $\mathrm{p}=0.9760$, $\mathrm{p}<0.0001$ ). The severity of the disease was mild in $22 \%$, moderate in $41 \%$, severe in $24 \%$, and very severe in $13 \%$ of patients. HRQOL was compared between men and women; the mean mental component summary scores were significantly higher in women (65.6 \pm 10.7$)$ than in men (59.2 \pm 11.6$)$. An inverse significant correlation between HRQOL and degree of dyspnea was observed $(\mathrm{p}=-0.9218, \mathrm{p}<0.0001)$.

Conclusion: The mental health status is essentially higher in women when contrasted with men. HRQOL is impaired, and moreover, it progressively worsens with increasing severity of the disease. This study shows that patients with higher smoking index are having more likelihood of developing the COPD disease and dyspnea has a great impact on HRQOL of patients. Evaluation of COPD patients should not be based only on pulmonary function tests but also by considering and estimating the patient's HRQOL.

Keywords: Health-related quality of life, Physical component summary, Mental component summary, Chronic obstructive pulmonary disease.

(C) 2017 The Authors. Published by Innovare Academic Sciences Pvt Ltd. This is an open access article under the CC BY license (http://creativecommons. org/licenses/by/4. 0/) DOI: http://dx.doi.org/10.22159/ajpcr.2017.v10i8.19199

\section{INTRODUCTION}

Chronic obstructive pulmonary disease (COPD) is a progressive and partially reversible obstruction of air flow related with lungs abnormal inflammatory response to gasses and different poisonous particles [1].

Over 3 million people died because of COPD in 2005 relating to $5 \%$ of all deaths globally and it is estimated to be the third leading cause of death by 2030. According to the World Health Organization estimates, 65 million people have moderate to severe COPD [2]. India contributes a noteworthy and developing rate of COPD mortality, which is assessed to be among the most elevated on the planet; i.e., more than 64.7 evaluated age institutionalized passing rate per 100,000 among both guys and females. This would mean around 556,000 in the event of India, which is over $20 \%$ out of a world aggregate of $2,748,000$ every year [3].

The most common manifestations of COPD are breathlessness, or a "requirement for air," excessive secretion of sputum, and cough. The objectives of COPD treatment are to prevent disease progression, enhance exercise tolerance, relieve symptoms, boost health status, prevent and manage exacerbations, prevention, and management of complications, and reduce the rate of mortality. COPD primary risk factors include tobacco smoking, indoor air contamination (such as biomass fuel utilized for cooking and warming), occupational dust and chemicals (vapors, irritants, and fumes), outdoor air pollution [4]. A basic test called spirometry can be utilized to diagnose COPD, which measures how profoundly a person can breathe and how fast air can move in and out of the lungs. Spirometry is required to make the analysis, the presence of a post-bronchodilator forced expiratory volume 1 (FEV1)/forced vital capacity $<0.70$ affirms the presence of persistent airflow limitation and thus of COPD in patients with appropriate symptoms and significant exposures to harmful stimuli, spirometry is the most reproducible and target measurement of airflow limitation in patients. It is a noninvasive and promptly accessible test [5].

The Global Initiative for Chronic Obstructive Lung Disease (GOLD) guidelines have identified the objectives of treatment for COPD patients, these include the patients' goals of improved emotional function (health-related quality of life [HRQOL]), exercise tolerance and critical clinical objectives, for example, prevent disease progression and minimization of symptoms [6]. Measures of HRQOL, along with estimations of morbidity and mortality rate, can also be used for making medical decisions regarding treatment because they include information on abilities, impairments, symptoms, and psychological effects of the disease [7].

The Short Form Health Survey (SF-12) scale scores are estimated for four of the health concepts (physical functioning, role-physical, role-emotional, and mental health) using two items each, whereas the remaining four (general health, bodily pain, vitality, and social functioning) are spoken by a single item [8].

This study mostly focuses on the HRQOL in COPD patients and to measure the difference of HRQOL based on COPD severity.

\section{METHODS}

\section{Study design}

A prospective observational study was conducted in the Department of General Medicine, in the Tertiary Care Hospital, Chennai, India. The study was conducted over a period of 9 months. A total of $100 \mathrm{COPD}$ 
patient's data were collected regarding patients age, gender, smoking status, and clinical characteristics. The study protocol was approved by the Institutional Ethics Committee.

\section{Patients}

Patients of both sexes, aged 18 years above, with a previous diagnosis of COPD (confirmed by medical history and spirometry) and patient willing to participate and complete the simple SF-12 questionnaire were eligible for the study. The diagnosis of the disease was performed according to the criteria of the GOLD based on the demonstration through a forced spirometry, post-bronchodilator FEV1. Spirometry ought to be performed after the organization of a sufficient measurement of no $<1$ short-acting inhaled bronchodilator keeping in mind the end goal to limit inconstancy. The COPD seriousness was evaluated by the constrained expiratory volume (FEV1) in one moment: That is gentle (FEV1 $\geq 80 \%$ anticipated), direct $(50 \% \leq \mathrm{FEV} 1<80 \%$ anticipated), extreme $(30 \% \leq \mathrm{FEV} 1<50 \%$ anticipated), and exceptionally extreme (FEV1 $<30 \%$ anticipated). The COPD severity was graded based on the FEV1 in 1 second: That is mild (FEV1 more than or equal to $80 \%$ predicted), moderate (FEV1 $\leq 50 \%$ or even $<80 \%$ predicted), severe (FEV1 less than or equal or even less than $50 \%$ predicted), and very severe (FEV1<30\% predicted). Pregnancy and lactating woman and those patients suffering from any physical and/or psychiatric disease were also excluded from this study. The patients with more than $80 \%$ of missing data in their medical records were also excluded from the study.

\section{Data collection}

Interviews were carried out during the ward rounds. All data were collected using a Short Form 12 Health Survey Questionnaire (SF-12), in which the following variables were recorded: Age; gender; smoking habit (current smoker, never smoker, and ex-smoker); year of COPD diagnosis; data's of the last spirometry measurement (FEV1 values).

Patients were administered with the Short Form 12 Health Survey Questionnaire (SF-12), which contains 12 items. These 12 items explain more than $90 \%$ of the variance of the physical and mental component scales. From them two scores can be calculated, the physical (physical component summary-12 [PCS-12]) and the mental (mental component summary-12 [MCS-12]) component summary. The SF-12 scores run from 0 to 100 , where higher scores indicate better HRQOL. A score more than 60 has been regarded as high HRQOL, 40-60 as normal HRQOL, and $<40$ as impaired (low) HRQOL. A standard Tamil version of the SF-12 questionnaire has been provided.

The Medical Research Council (MRC) dyspnea scale was employed to analyze the degree of breathlessness by relating to activity in this study population.

\section{Statistical analysis}

The GraphPad Prism 5.01 was used for the analysis of data. Continuous variables are expressed as the mean and standard deviation (SD), whereas the qualitative variables are described as percentages. Differences of HRQOL of patients based on the severity of COPD were analyzed with the paired Student's t-test and the confidence intervals were calculated at the 95\% level. The Spearman's rank-order correlation coefficient $(\rho)$ was calculated to assess the relationship between HRQOL, FEV1, and Dyspnea. Statistical significance was set at $\mathrm{p} \leq 0.05$.

\section{RESULTS}

The total study population of 100 patients, $78 \%$ were men and $22 \%$ of women; with a mean $( \pm$ SD) age of $65.4 \pm 13$.2 years. This study shows that $48 \%$ were ex-smokers and $22 \%$ were current smokers and $30 \%$ were never smokers. Patients demographic is shown in Table 1.

With regard to the last spirometry measurements, the mean FEV1 value was $57.2 \pm 10.4$. The severity of COPD disease was mild in $22 \%$ of cases, moderate in $41 \%$, severe in $24 \%$, and very severe in $13 \%$ as shown in
Table 2. There were differences in COPD severity according to gender, with significantly higher percentages of men compared to women.

Most of the patients (63\%) had a moderate degree of dyspnea (MRC dyspnea scale: Grade 2). However, $16 \%$ of men showed a moderately severe degree of dyspnea (MRC dyspnea scale: Grades 4 and 5) compared with $21 \%$ of women.

The mean PCS-12 and MCS-12 scores were $40.7 \pm 9.4$ and $64.3 \pm 12.1$, respectively. General health and physical functioning domains were those with the lowest scores (i.e., physical health domain) as shown in Fig. 1, whereas role emotional and social functioning domains were those with the highest scores (i.e., mental health) were presented in Table 3.

Based on the results of the SF-12 questionnaire, HRQOL was graded as normal ( $40-60$ points) by $64 \%$ of patients and lower ( $<40$ points) by $36 \%$ of patients. When HRQOL in men and women was compared, there

Table 1: Patients demographic and clinical characteristics

\begin{tabular}{lll}
\hline Characteristics & Number (\%) & Mean \pm SD (range) \\
\hline Total no of patients $(\mathrm{n}=100)$ & 100 & \\
Sex & & \\
$\quad$ Men & $78(78)$ & \\
$\quad$ Women & $22(22)$ & \\
Age groups (years) & & \\
$30-39$ & $4(4)$ & $65.4 \pm 13.2$ \\
$40-49$ & $11(11)$ & \\
$50-59$ & $16(16)$ & \\
$60-69$ & $26(26)$ & \\
$70-79$ & $33(33)$ & \\
$\geq 80$ & $10(10)$ & \\
Smoking & & \\
Never & $30(30)$ \\
Ex-smoker & $48(48)$ & \\
Current smoker & $22(22)$ \\
\hline
\end{tabular}

SD: Standard deviation

Table 2: Clinical characteristics of patients

\begin{tabular}{lll}
\hline Characteristics & Number (\%) & Mean \pm SD (range) \\
\hline FEV1\% predicted & & $57.2 \pm 10.4$ \\
Severity of COPD & & \\
Mild & 22 & \\
Moderate & 41 & \\
Severe & 24 & \\
Very severe & 13 & \\
\hline
\end{tabular}

SD: Standard deviation, FEV: Forced expiratory volume, COPD: Chronic

obstructive pulmonary disease

Table 3: HRQOL in COPD patients by using the SF-12 Questionnaire

\begin{tabular}{ll}
\hline SF-12 scale & Mean \pm SD \\
\hline Physical functioning & $39 \pm 30.2$ \\
Role physical & $45.1 \pm 35.7$ \\
Bodily pain & $63.4 \pm 29.3$ \\
General health & $31.8 \pm 18.5$ \\
Vitality & $44.6 \pm 25.1$ \\
Social functioning & $66.4 \pm 27.6$ \\
Emotional role & $73.4 \pm 42.2$ \\
Mental health & $62.8 \pm 22.5$ \\
PCS-12 & $40.7 \pm 9.4$ \\
MCS-12 & $64.3 \pm 12.1$ \\
\hline
\end{tabular}

SD: Standard deviation, PCS-12: Physical component summary-12, MCS-12: Mental component summary-12, COPD: Chronic obstructive pulmonary disease, HRQOL: Health-related quality of life 
were no significant differences in the mean PCS-12 scores (40.4 \pm 10.1 versus $39.3 \pm 9.7$ ), but the mean MCS-12 scores were significantly higher in women $(65.6 \pm 10.7)$ than in men $(59.2 \pm 11.6)$.

HRQOL correlated significantly with FEV1 values $(\mathrm{p}=0.9760, \mathrm{p}<0.0001)$. The mean scores of the PCS and the MCS in COPD patients according to the severity of the disease were illustrated in Fig. 2. As expected, an inverse significant correlation between HRQOL and degree of dyspnea was observed $(p=-0.9218, p<0.0001)$.

\section{DISCUSSION}

In COPD patients, the measurement of HRQOL has currently achieved widespread acceptance [9]. The objective of this study was to determine HRQOL in COPD patients and also to measure the differences in their quality of life according to gender, and severity of the disease. The Short Form Health Survey (SF-12) has been shown to be a valid evaluation tool with excellent measurement properties in patients with chronic respiratory conditions such as COPD and asthma. This health survey questionnaire allows calculating the physical health status and the mental health status of the patient when administered to all patients [10-13].

In most of the patients, lower PCS-12 physical health component summary scores than that of the MSC- 12 mental health component summary scores in patients with COPD has been reported [14].

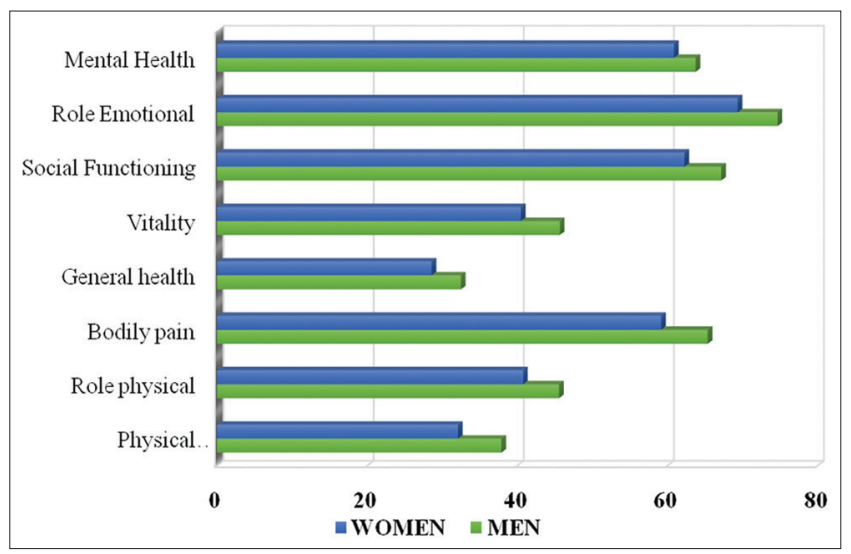

Fig. 1: Mean scores of the physical component summary-12 and the mental component summary-12 in chronic obstructive pulmonary disease patients according to gender

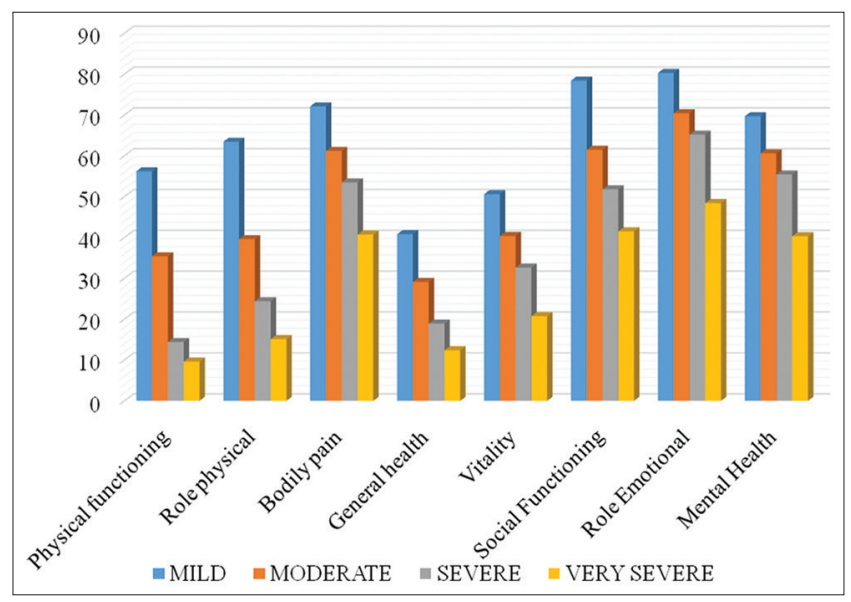

Fig. 2: Mean scores of the physical component summary and the mental component summary in chronic obstructive pulmonary disease patients according to the severity of the disease
Another study shows that there is a moderate association between COPD severity and HRQOL using FEV1\% value and also observed that within each stage of severity there is a large variation in deterioration; accordingly both clinical and HRQOL measures ought to be considered in the evaluation of the COPD patients [15]. The relationship between disease severity and HRQOL was made using FEV1\%, HRQOL was predicted by staging the disease, based on the GOLD and British Thoracic Society guidelines [16]. In a COPD case finding a program in community pharmacists as another technique to decrease COPD under diagnosis, drug specialists could choose and evaluated patients utilizing a survey and spirometry testing [17]. Furthermore, a study demonstrates that even with the minor change in FEV1 values, patients felt much better, due to which their HRQOL enhanced to a greater extent [18].

Ozalevli and Ucan [19] observed that MRC based dyspnea score was compared with spirometry measurement FEV1 values and reported that dyspnea has a greater impact on HRQOL than spirometry or functional measurements in the COPD patients. The most commonly used scale to measure dyspnea is MRC scale, because of its simplicity, ease of administration and established validation as a useful marker in COPD, and the study concluded that MRCS as the most suitable scale used in COPD patients [20]. Hajiro et al. [21] showed that dyspnea is the main factor that separates disease-specific health-related quality of life and analyzed that it has a strong correlation with impairments in the HRQOL in COPD patients. According to Oga et al.'s [22] study showed that different significant characteristics are observed from different dyspnea measurements; it is important to follow dyspnea using appropriate measurements. Increase airflow limitation was not only compared with the progressive dyspnea, but also with other factors such as psychological status or worsening of diffusing capacity of the patient.

Males are prone to develop COPD, the high prevalence rate in males is due to a higher prevalence of smoking in this gender, and moreover, females are less exposed to smoking when compared to males [23]. Prigatano et al. [24] reported that quality of life was affected due to smoking regardless the presence of COPD. Younger COPD patients reported with worse quality of life and current smoker patient with high FEV1 values than ex-smoker patients with COPD and also concluded that COPD severity was influenced by smoking status, but current smoking affected the quality of life by causing COPD exacerbations although it did not have a direct impact on quality of life deterioration.

In Fletcher and Peto's [25] study, COPD is described by a dynamic decrease in FEV1 with age. In light of this, more established age individuals anticipated that would have COPD. The review proposed that analysis and medicinal treatment ought to be given by considering both biomedical and psychosocial impacts.

\section{CONCLUSION}

This study shows that there were contrasts in COPD seriousness as per sexual orientation, with altogether higher rates of men contrasted with women. There is no critical physical well-being distinction among men and women, but the mental health is significantly higher in women when compared to men. HRQOL is impaired, and moreover, it progressively worsens with increasing severity of the disease. This study shows that patients with higher smoking index are having more likelihood of developing the COPD disease and dyspnea has a great impact on HRQOL of patients. Psychological assessment is important for improving COPD patients' symptoms, HRQOL, and better treatment. In conclusion of this study, dyspnea greatly impacts the HRQOL of patients with COPD and evaluation of COPD patients should not be based only on pulmonary function tests, but rather additionally in view of estimation of patient's HRQOL.

\section{ACKNOWLEDGMENT}

The authors are grateful to the administration of Vel's University and the Tertiary care Hospital for providing necessary facilities for the fulfillment of the work. 


\section{REFERENCES}

1. Global Initiative for Chronic Obstructive Lung Disease - GOLD Guideline: Global Strategy for the Diagnosis, Treatment, and Prevention of Chronic Obstructive Pulmonary Disease; 2011. Available from: http://www.goldcopd.com.

2. World Health Organization. Burden of COPD. Available from: http:// www.who.int/respiratory/copd/burden/en.

3. Lopez AD, Shibuya K, Rao C, Mathers CD, Hansell AL, Held LS, et al. Chronic obstructive pulmonary disease: Current burden and future projections. Eur Respir J 2006;27(2):397-412.

4. World Health Organization Information about COPD. Available from: http://www.who.int/respiratory/copd/en.

5. Global Initiative for Chronic Obstructive Lung Disease, Pocket Guide to COPD Diagnosis, Management, and Prevention: A Guide for Health Care Professionals; 2017 edition. Available from: h t t p : / / w w w . goldcopd.org/wp-content/uploads/2016/12/wms-GOLD-2017-PocketGuide.pdf.

6. Pauwels R, Buist A, Calverley P, Jenkins C, Hurd S. Global strategy for the diagnosis, management, and prevention of chronic obstructive pulmonary disease. Am J Respir Crit Care Med 2001;163(5):1256-76.

7. Curtis JR, Martin DP, Martin TR. Patient-assessed health outcomes in chronic lung disease: What are they, how do they help us, and where do we go from here? Am J Respir Crit Care Med 1997;156:1032-9.

8. Ware JE, Kosinski M, Keller SD. How to Score the SF-12 Physical and Mental Health Summary Scales. $2^{\text {nd }}$ ed. Boston, MA: The Health Institute; 1995.

9. Domingo-Salvany A, Lamarca R, Ferrer M, Garcia-Aymerich J, Alonso J, Félez M, et al. Health-related quality of life and mortality in male patients with chronic obstructive pulmonary disease. Am J Respir Crit Care Med 2002;166(5):680-5

10. Katz PP, Eisner MD, Yelin EH, Trupin L, Earnest G, Balmes J, et al. Functioning and psychological status among individuals with COPD. Qual Life Res 2005;14(8):1835-43.

11. Garratt AM, Hutchinson A, Russell I. Patient-assessed measures of health outcome in asthma: A comparison of four approaches. Respir Med 2000;94(6):597-606.

12. Miravitlles M, Calle M, Alvarez-Gutierrez F, Gobartt E, López F, Martín A. Exacerbations, hospital admissions and impaired health status in chronic obstructive pulmonary disease. Qual Life Res 2006;15(3):471-80.

13. Miravitlles M, Ferrer M, Pont A, Zalacain R, Alvarez-Sala JL, Masa F, et al. Effect of exacerbations on quality of life in patients with chronic obstructive pulmonary disease: A 2 year follow up study. Thorax 2004;59(5):387-95.

14. Ståhl E, Lindberg A, Jansson SA, Rönmark E, Svensson K, Andersson F, et al. Health-related quality of life is related to COPD disease severity. Health Qual Life Outcomes 2005;3:56.

15. Ferrer M, Anto JM, Alonso J, Prieto L, Plaza V, Monso E, et al. Quality of life in COPD patients of different stages of the disease. Eur Respir J 1995;8:354.

16. Ferrucci L, Baldasseroni S, Bandinelli S, De Alfieri W, Cartei A, Calvani D, et al. Disease severity and health-related quality of life across different chronic condition. J Am Geriatr Soc 2000;48:1490-5.

17. Giner J, Roura P, Torres B, Burgos F, Castillo D, Tarragona E, et al. Knowledge, attitudes and preferences among Spanish community pharmacists regarding inhaled therapy (the optim pharmacy study). Int J Pharm Pharm Sci 2016;8(9):53.

18. Altaf M, Masood Q, Ahmed T, Ilyaz M, Basha SA. Health related quality of life assessment using St. George's respiratory questionnaire in chronic obstructive pulmonary disease patients on combined inhaled corticosteroids and bronchodilators. Int J Pharm Pharm Sci 2015;8(1):445

19. Ozalevli S, Ucan ES. The comparison of different dyspnoea scales in patients with COPD. J Eval Clin Pract 2006;12(5):532-8.

20. von Leupoldt A, Hahn E, Taube K, Schubert-Heukeshoven S, Magnussen H, Dahme B. Effects of 3-week outpatient pulmonary rehabilitation on exercise capacity, dyspnea, and quality of life in COPD. Lung 2008;186(6):387-91.

21. Hajiro $T$, Nishimura $K$, Tsukino $M$, Ikeda $A$, Oga $T$, Izumi $T$. A comparison of the level of dyspnea versus disease severity in indicating the health-related quality of life of patients with COPD. Chest 1999;116(6):1632-7.

22. Oga T, Tsukino M, Hajiro T, Ikeda A, Nishimura K. Analysis of longitudinal changes in dyspnea of patients with chronic obstructive pulmonary disease: An observational study. Respir Res 2012;13:85.

23. Postma S, Kerstjens A. Epidemiology and natural history of chronic obstructive pulmonary disease. In: Gibson G, John G, Corrin B, editors. Respiratory Medicine. Ch. 11. Philadelphia, PA: Saunders; 2003. p. 1109-20.

24. Prigatano GP, Wright EC, Levin D. Quality of life and its predictors in patients with mild hypoxemia and chronic obstructive pulmonary disease. Arch Intern Med 1984;144(8):1613-9.

25. Fletcher C, Peto R. The natural history of chronic airflow obstruction. Br Med J 1977;1(6077):1645-8. 